DOI: 10.24234/wisdom.v17i1.440

Kadzhik OGANYAN, Vladimir OGORODNIKOV, Vladimir PYZH, Svetlana ROSENKO

\title{
GNOSEOLOGY-BASED ANALYSIS OF THE RELATIONSHIP BETWEEN TRUTH AND FALLACY ${ }^{1}$
}

\begin{abstract}
This article concerns the concept of fallacy in its dialectical relation to truth in scientific understanding. It highlights a variety of definitions attempting to clarify the meaning of fallacy, which is ground zero for the authors' definition of the aforementioned concept. It is stated that fallacy is the necessary step towards truth. It is explained why fallacy cannot be identified with incomplete knowledge, logical fallacies and falsehood. Also, this article highlights the main doctrinal philosophical and methodological foundations of fallacies and criteria for defining the truth.

Keywords: truth and fallacy, criteria of truth, logicalness and verity, fallacy and falsehood, fallacy and psychological illusion, fallacy and idealism.

Introduction

Knowledge is not the only result of cognitive processing. It should be recognized that one often encounters real knowledge alongside various kinds of fallacies in striving to find the truth.

1 The issues considered in this article have been discussed from different perspectives in a number of works by the authors. In particular see: Oganyan, K. M. (2014). Vzaimosvyaz' znaniya, i mneniya: gnoseologicheskiy analiz (The Relationship between Knowledge and Opinion: An Epistemological Analysis, in Russian). Wisdom, 1(2), 103-116; Oganyan, K. M. (1986). Vidy teoreticheskogo znaniya i ikh vzaimootnosheniye (na materiale yestestvennonauchnykh teoriy) (Types of Theoretical Knowledge and Their Relationship (Based on Natural Science Theories), in Russian). Leningrad: LGU; Oganyan, K. M. (1983). Genezis vidov teoreticheskogo znaniya (metodologicheskaya kontseptsiya) (The Genesis of the Types of Theoretical Knowledge (Methodological Concept), in

In particular, epistemic circumstances that the latter are expressed in different forms, including psychological illusions, logical errors, various prejudices, incorrect guesses, assumptions, false opinions, beliefs, preconceptions and the like.

It is important to note that regardless of the

yan, K . M. (1984), Priroda i osnovnyye kharakteristiki nauchnogo znaniya (The Nature and Main Characteristics of Scientific Knowledge, in Russian). Bulletin of Social Sciences of the Academy of Sciences of Armenia, 11; Oganyan, K. M., Branskiy, V. P., Hovhannisyan, A. O., \& Djidjian, R. Z. (2018). Metodologicheskiy analiz genezisa nauchnoy teorii: vidy yestestvennonauchnogo znaniya i ikh vzaimosvyaz' (Methodological Analysis of the Genesis of Scientific Theory: Types of Natural Science Knowledge and Their Relationship, in Russian). Saint Petersburg: SPbGEU; Oganyan, K. M. (2019). Filosofiya i metodologiya sotsial'nykh nauk (Philosophy and Methodology of Social Sciences, in Russian). 2nd ed., Rev. and add. Moscow: Yurayt Publishing House.
\end{abstract} Russian). Science and Society, VI, 114-119; Ogan- 
form of their manifestation, fallacies play a prominent role in the integral process of spiritual comprehension and human development of the world, acting either as a stimulus or a deterrent.

In ancient times, Plato (1970) argued that fallacies were the same legitimate components of knowledge as knowledge itself in contrast to Protagoras, who denied the very possibility of fallacies (pp. 250-253). Moreover, very often, the meaning and the relative weight of fallacies in cognition and human activities is much higher than true knowledge. G. V. Leibniz (1936), for example, noted that "Indeed, among individuals, there is a higher level of fallacies as compared to knowledge" (p. 405).

However, in reality, the fallacy is an important and, in a certain sense, necessary aspect of dialectically developing cognitive processes. This is a stage in our realization of the truth and not a random fact or an honest mistake.

As mentioned above, the relevance of the analysis of the reasons and grounds for fallacies, their dialectical links with truth are as relevant as ever.

\section{Methodological Framework}

Since the occurrence of scientific knowledge (historically and logically coinciding with the formation of a philosophical belief), the problem of the difference between truth and fallacy and looking for the appropriate criterion for this difference have been essential tasks for science at all times, until today. A number of such criteria have been suggested in the history of science. Most often, the methodologies for discovery and grounding these criteria relied on subjective postulates while maintaining these criteria.

In the account of this, let us consider some most relevant versions formulating criteria of truth suggested by the thinkers of the New and the Newest time. "Clarity, distinctness and evidence", the criteria of a true statement proposed by R. Descartes (1989, p. 260), are referred to as subjective forms of the statement, while already ancient Greek philosopher Plato (427-348 BC) associated the truth with the objective content of the statement: "He who speaks about things in accordance with what they really are, tells the truth, otherwise, he is mistaken".

A.A. Bogdanov (Malinovsky) (1873-1928), who was an economist, philosopher, politician and natural scientist, presented the truth as "an organizing form of collective experience" in his work "The Philosophy of Living Experience" (1913). Following this, he presents the criterion of truth as general validity meaning something in agreement with most workers in this area of activity. However, it turns out that the truth can be discovered by putting the matter to a vote! This position was not only a variant of subjective idealism, but it was also a return to the idea that was critically assessed by the thinkers of the past. Already Heraclitus pointed out that "a large majority of individuals make less sense than one brilliant mind". "It is completely useless," Descartes (1989) noticed, "to count the votes in order to follow the opinion of the majority of the authors, for when it comes to a difficult question, it is more likely that the truth is on the side of the minority but not the majority" (p. 265). However, universal and equal suffrage and referendum are considered to be the most democratic means of the citizens' will in favour of some important decisions in the world today.

William James (1842-1910), one of the founders of pragmatism, defined the truth as the utility, or expedience of an idea, "true means simply beneficial in our way of thinking". This definition of truth is the most critical point in the 
doctrine of pragmatism. We are witnessing the absolutization of the role of success and its transformation not only into the only criterion for the truth of ideas but also into the very content of the concept of truth. However, not only truth but also falsehood as its deliberate distortion can bring practical benefit and great success.

Verifiability principle received the status of the criterion of the truth of the statement meaning ensuring comparability of the statement with direct evidence of sensory experience in the philosophy of neopositivism (its main representatives are: M. Schlick (1882-1936), R. Carnap (1891-1970), L. Wittgenstein (1889-1951), B. Russell (1872-1970)).

However, the verification criterion is not identical to the practice criterion since not every applied abstraction can be verified (e.g., all arguments about the past and some distant future). In addition, processes that are fundamentally unobserved in the microcosm and many mega-level interactions do not lend themselves to comparison with direct sensuous experience (this was the ground both for "physical idealism" of the early $20^{\text {th }}$ century and today' quantum-mechanical idealism). Among other things, the sensuous experience is always subjectively limited and abstracted, which provides grounds for qualifying the principle of verification as a subjectively idealistic criterion of truth.

Clarification of the insolvency of the principle of verification led the representatives of neopositivism, above all O. Neurath (1882-1945) and R. Carnap, to the creation of the concept of coherence, according to which a statement must be recognized as true if it is logical, internally consistent and does not contradict another statement within the theory. However, again such an approach (as already in Descartes) is the identification of the objective content of a statement, with which the problem of its truth, its form and logical structure can only be compared. This approach equates Ptolemaic and Copernican systems, the atomism of Democritus and modern atomic physics and makes them equally valid.

The only method, which is the method of practical verification, is an attempt to embody one's view of a particular process in this entire process. The use of it already allowed primitive man to find out whether he was mistaken in his views and allows modern man to do the same. The problem of practical verification of the truth of our assumptions about the world cannot be solved without clarifying the concept of "practice" and defining the place and role of practice in cognitive processes.

Practice embodies sensuous objective and rational conceptual (purposeful) joint activities of people in their mastering and transforming natural and social processes.

The authors of this article consider the method of practical verification of the truth of statements to be genuine scientific and consistent with the methodology of cognition. We will rely on this method in our further analysis of the essence of truth and fallacy.

\section{The Problem and the Ways of Its Solution}

For a more accurate understanding of a fallacy, its nature and sources it seems appropriate to distinguish psychological, epistemological and logical sources of its origin and existence.

Before consistently considering the abovementioned sources of fallacy, it is necessary to give at least a preliminary working definition of the concept of "fallacy". Without this procedure, it is senseless to look for the sources of the phenomenon, the nature of which has not been clari- 
fied.

In the modern philosophical literature, there are many definitions of fallacy. Some of them complement and specify this concept's content, and some definitions obviously come in contrast with each other (and sometimes with themselves) in terms of formal logical contradictions.

In "Contemporary Encyclopedia of Philosophy", I. T. Kasavin (2010) interprets "fallacy" as a simple discrepancy between knowledge and its object or incompatibility with accepted knowledge (p. 32). "A discrepancy between knowledge and its object" speaks of the inadequacy of knowledge to what is being cognized that is of the untrue knowledge. In this case, we can conclude that fallacy is the alternative to truth.

Incompatibility of this knowledge with "widely accepted knowledge" is an entirely different situation. In this situation, knowledge is compared with other knowledge, but it is not compared with an object. In this case, the revealed incompatibility does not really mean that evidenced-based knowledge about the object is untrue because "widely accepted knowledge" that is conventional knowledge may turn out to be untrue. Therefore, it is not clear what the author mentioned above defines the concept of "fallacy", as his two definitions are connected through the coordinating conjunction "or" are logically incompatible themselves.

"Fallacies and errors in the dialectical process of cognition mean the incompleteness and infiniteness of display", writes P. S. Zabotin in his monograph devoted to fallacy. Such an understanding would be satisfactory if fallacy and knowledge resulted from a simple, immediate reflection of the surrounding reality produced by a passive, contemplative subject. The difference between them can be seen only in the fact that knowledge is an adequate reflection, and the fal- lacy is a distorted and inadequate one. The fallacy is defined as an "inappropriate, incorrect, onesided reflection of objects, phenomena and human consciousness" in "Logical Dictionary" by N. I. Kondakov (1975, p. 177).

Obviously, almost all the results of the subject-object interaction would have to be referred to as fallacy as well as all the products displaying reflection due to their fundamental incompleteness if we adhere to the above-mentioned understanding.

It must, therefore, be concluded that that fallacy is characterized by incomplete knowledge, and it is the same as untrue knowledge. Thus, fallacy can be characterized as the alternative to truth representing untrue knowledge about objects of knowledge performed through appropriate arguments.

Such a kind of fallacy cannot be a ground for excluding fallacy from the process of cognition as something merely negative. F. Engels $\left(1961^{\mathrm{a}}\right)$ observed that "alchemy was necessary for due time" (p. 277), although the goal of alchemists, which was a fallacy, consisted in creating the Philosopher's Stone which was supposed to transform lead into gold.

However, the main goal of alchemical experiments was obtaining the Elixir of Life, bestowing immortality on the person who possessed it, helping to preserve youth and health for many decades and even centuries. Following their goal and using trial and error method based on sometimes tragic fallacies, alchemists managed to obtain a variety of biochemical compounds which were used as real medicines for curing diseases affecting people. In this sense, alchemy was the forerunner of pharmaceutics. It is interesting that some outstanding scientists were interested in alchemy. For example, it is known that Isaac Newton devoted about 30 years 
of his life to alchemical experiments. Alchemists made essential contributions to the development of inorganic and organic chemistry. Many of them glorified their names in making outstanding discoveries. Basilius Valentinus (Basil Valentine), who was a Benedictine monk living in Erfurt, Germany, in the second half of the $15^{\text {th }}$ century, discovered hydrochloric and sulfuric acid, Paracelsus (1493-1541), who was a Swiss physician and alchemist, found a way to obtain zinc. A German philosopher and theologian, Albert the Great (about 1206 - 1280) found a technology to obtain cinnabar, white lead and red lead. All of the above-mentioned discoveries were made in the process of persistent and dedicated understanding and overcoming numerous fallacies.

The fact that a sharply negative attitude towards the phenomenon of fallacy as the one which does not express its essence and therefore subject to immediate elimination remained unchanged all through the period of concrete scientific and philosophical comprehension of knowledge. This fact led to a significantly lower degree of development of the problem of a fallacy than the problems of true knowledge. More recently, it is becoming clearer and clearer that the scientific understanding of the cognitive process is impossible without the analysis of fallacy.

Classical philosophical literature is full of numerous, sometimes very interesting, witty and accurate arguments about the essence and causes of the occurrence and consolidation of untrue submissions, illusions and mistakes in the individual and public consciousness. The conflict of tendencies of psychologization and using the logical framework for the cognitive process characterizing public consciousness significantly affect the interpretations of the essence of natural and social processes.

Contradictions largely determine contradic- tory interpretations of fallacy's essence in determining the causes of the occurrence of fallacies in cognitive processes. Almost all representatives of pre-Marxist European philosophy typically looked for the causes of fallacies in the biological or psychological nature of people cognizing the world, their physiology, generic cognitive abilities and their imperfection, to be more precise. Such a tendency in understanding the reasons for fallacy, providing not only their inevitability, necessity but also their insurmountability, is associated with already ancient ideas proclaiming that feelings, sensuality and eagerness for body activities prevent humans from achieving proper knowledge. Modern biologizing interpretations of the emergence of inadequate reflection of objective reality are based on the latest data of physiological sciences. This allows us to reveal the natural prerequisites of illusions, hallucinations and other sensuous images, but this is not directly related to the elucidation of the epistemological essence of fallacy.

Psychological interpretations of the reasons, and, therefore, the essence of fallacy, were characterized as not so limited and thus more attractive and acceptable, and still, they often seem to be. In fact, the representatives of the rationalistic and empirical-sensualist traditions debated among themselves within the above-mentioned frame. Thus, if the former considered sensations and perceptions to be illusory and deceiving and defined thinking as initially clear, distinct and reliable, the latter, on the contrary, were sure that fallacies happen in case of separation of thinking and sensations, as sensations themselves are infallible and reliable.

Presenting the views of R. Descartes, B. Spinoza (1957) highlights his idea that "fallacy comes from a simple abuse of our will" (p. 214). Explaining the reasons for the delusion, B. Spi- 
noza bases himself on the psychological concept of "imagination". In his opinion, "The lie is defined as something we perceive about an object, and we often imagine (despite the fact that we have learned little from it) that the total object affirms or denies this perception about itself as a whole" (Spinoza, 1957, p. 140). Also, following R. Descartes and detecting a discrepancy between the volumes of knowledge and will, Spinoza identified this fact with the most important condition for fallacy emerging. Postulating the primacy of will over the intellect, A. Schopenhauer speculated similarly.

The role of psychological components of the personality structure in the formation of fallacies was absolutized by E. Mach. Considering various kinds of fallacies, including illusions of sensation and perception, distorted representations, inadequate sensory images, he created his concept of fallacy under a more general concept of "psychic experience", coinciding, in his opinion, with knowledge in general. According to E. Mach, "All knowledge is a psychic experience... If a judgment contradicts the corresponding experience, we call it fallacy... Fallacy and knowledge originate from the same psychic sources" (Mach, 1909, pp. 121-122).

Truth or fallacy refers to the logical aspect of our consciousness, for both of these phenomena are represented in the ideas of arguments. We can conclude whether they are true or are represented as variants of fallacies only in relation to the arguments given. It is only arguments that are able to be checked for being the true ones using practice as the criterion of truth as they state or deny something in relation to their subject. Concepts are treated as abstracts containing only essential general characteristics of a certain set of cognizable moments of reality. Even the definition of a concept revealing its content (that is, its essential general characteristics) is always represented by arguments and statements.

Idealistic philosophical postulates can be a source of fallacies. Thus, an outstanding dialectician G. Hegel came to a mistaken attitude regarding the development of the world which was based on his philosophical system of absolute objective idealism. He declared that the fundamental idea comes to the final result of its development in the consciousness and practice of contemporary society. The then Prussian monarchy seemed to Hegel to be the highest level of statehood development. This is what was the contradiction between the worldview and the dialectical method, which did not postulate the completion of development. As F. Engels noted, "For dialectical philosophy, there is nothing once and for all established, unconditional and sacred. This philosophy presumes the presence of the stamp of the inevitable fall in everything, and nothing can resist it except for the continuous process of occurrence and destruction as well as the endless ascent from the lowest levels to the highest ones. This very philosophy is just a simple reflection of this process in the thinking brain" (Engels, 1961 c, pp. 275-276).

As for the epistemological sources of fallacy, the most prominent thinkers of the past interested in the problem of fallacy used to equate its reason and a lack of knowledge of a particular subject when describing a cognitive process. In one of his theorems, "Ethics", Spinoza (1957) argued that "fallacy consists of a lack of knowledge characterized by inadequate, that is distorted and vague ideas" (p. 44). Identifying cognition with mental processing, the representatives of rationalism looked for fallacies in the processes of generalization, incorrect analogies and assumptions that are in logical errors.

Epistemological bases of fallacies in philos- 
ophy in their clearest and most detailed form were revealed in connection with the criticism of religion (religious fallacies). In general, French materialists of the $18^{\text {th }}$ century explained the reason for substituting knowledge by faith mainly by the absence or, at least, insufficient knowledge and the lack of enlightenment in people.

Epistemological and logical "roots" of occurrence of fallacies in cognitive processes are clearly distinguished in the classical philosophical literature. Not only one of the most important reasons for education and existence but, in some cases, one of the most important reasons for the successful functioning of fallacies as those which are logically relevant to the truth are explained by indirectness and ambiguousness of any act of cognitive reflection.

At the same time, it is clear that the matter is not about only the internal difficulties of implementing cognitive processing. The reasons for the occurrence of fallacies are offered in many modern philosophical works synthesizing these above-mentioned psychological, logical and epistemological approaches. At the same time, these approaches are fundamentally different from each other in principle, and they are placed in diverse aspects of knowledge. Therefore, it is impossible to find a universal ground for such a synthesis. However, some authors regard the social environment as a synthesizing ground for various preconditions of fallacies.

Of course, knowledge is woven into a specific social, historical and cultural context, which inevitably marks its imprint upon all its results and, of course, upon the formation of fallacies. K. Marks and F. Engels emphasized the importance of the social division of labour and the alienation of social consciousness from social reality in connection with revealing the sources of "erroneous" or "perverted" (in their terminol- ogy) idealistic consciousness.

One of the signs of distorted reflections of the real world in the consciousness of the knower, according to Karl Marks, is a fetishistic illusion, in which consciousness concentrates on visibility, taking it for essence. The objective source of this distortion is the continually manifested discrepancy between the external existence and the essence. "If the form of manifestation and the existence of things coincided directly, any science would be superfluous" (Marks, 1962, p. 384).

Simultaneously, it is necessary to emphasize the existence of the fundamental difference between the epistemological and the logical grounds of fallacies. This circumstance is linked with the identification of logic and truth, which is still in force today. Let us emphasize that formal logic makes it possible to establish the correctness of the definitions of concepts and the formation of judgments and conclusions but does not imply their validity.

A criterion for the scientific nature of mental constructions, logicality also acts as a necessary but insufficient condition for achieving true knowledge. Thus, if a logical error can act as a ground for fallacy, a strictly logical construction does not protect us from fallacies not only in everyday life but also in scientific knowledge.

Claudius Ptolemy's geocentric system of the universe is a shining example of an utterly logical construction of fallacy, which was recognized as a valid theory for one and a half millennia precisely because of its logicality. Logicality as the capability for correct and valid reasoning is still the primary weapon for the manipulation of mass consciousness. "Iron" logic of constructing grandiose fallacies comes into force where blind faith cannot "work". Even some great minds often identifying conceptual and objec- 
tively real frameworks can be fascinated by the fact that constructions are purely logical, which is evident in modern cosmology and cosmogony especially (Ogorodnikov \& Oganyan, 2020). As for the aspect of everyday knowledge, it would not be a great exaggeration to state that in the $21^{\text {st }}$ century, as well as in all the times of the existence of homo sapiens, the absolute majority of the world's population is located in captivity of various kinds of fallacies in the form of parascientific mythologemes about the development of nature and society (Ogorodnikov, 2019). All kinds of scientific and everyday interpretations of the nature and causes of the global Covid-19 as a pandemic are sufficient arguments for this thesis.

The identification of the reasons and conditions for occurrence, existence and consolidation of fallacious beliefs is closely connected with the interpretation of their nature and etymologizing. Numerous attempts of gradation of types of fallacies on different grounds are known. Leaving aside this serious, complex and independent problem, let us turn to the philosophical understanding of knowledge and clarification of the epistemological meaning of the concept of "fallacy", its place in the conceptual apparatus of the theory of knowledge and thereby its relationship to knowledge, which is of particular relevance for the necessary purposes of this research.

Fallacy, as a necessary and, in a way, the inevitable phenomenon of knowledge conditionned by its internal logic, acts as a relatively independent step-by-step approach for constructing a framework for knowledge (truth).

For the first time, the fallacy in the Hegelian sense is understood as the condition for the attainment of truth, the development of knowledge and the "torment" of truth. In his Phenomenology of Spirit, G. W. F. Hegel condemns and even ridicules the opinion according to which truth and fallacy are isolated from each other. Both truth and fallacy equally occur in cognitive processes forming the most important moments of these processes. From the standpoint of dialectics, truth and fallacy represent the unity and struggle of opposites representing the driving force of cognitive development.

Achieving knowledge does not mean the impossibility of complete eliminating fallacies from cognitive processes. However, this circumstance does not mean that fallacies are inherent in any specific scientific research. There are some successful options for problem solving in a cognitive process while avoiding fallacies.

The epistemological essence of fallacies is determined by the process of reflection as the fundamental ground for cognition. "All ideas are based upon experience," - wrote F. Engels in this regard. "They are real or distorted reflections of reality" (Engels, 1961'a , p. 629).

A special role in the occurrence and formation of fallacies is played by the well-known nonlinearity, the incompleteness of the reflection at each separate stage, the lack of complete identity of the image and the object and the fundamental incompleteness of the adequacy of the image to the object. "The infinity of absolute thinking is made up of an infinite set of certain human heads working side by side on this infinite knowledge, and their successive generations are characterized by making practical and theoretical mistakes, resulting from unsuccessful, one-sided and false premises, following false, crooked and unreliable ways and regular missing correct solutions even when running into them" (Engels, 1961 ${ }^{\mathrm{b}}$, p. 549). This is facilitated by the objective inexhaustibility of cognitive objects and limited capacities of concrete historical subjects. 
Considering that any epistemic image resulting from cognitive outcomes is a product of the synthesis of reflection and a value-evaluative attitude of the knower towards it, one should not equate fallacies with simple inadequacy. Meanwhile, the analysis of the definitions of fallacies available in several current scientific papers shows that, as a rule, they are defined as stated above, e.g., as in the above-cited article by I. T. Kasavin. At the same time, despite such characteristics, it is considered acceptable to consider fallacy as a kind of knowledge as long as the previously identified broad understanding of the concept of "knowledge" (like any form of reflection and cognition) is used. However, I. T. Kasavin rightly notes that exaggerating the role of fallacy in cognition leads to relativism, scepticism and agnosticism (Kasavin, 2010, p. 32).

It is interesting to consider the conception of "fallacy" from the standpoint of theology, beliefs and dogmas of Holy Scriptures, the Holy Koran and other holy books. Truth is logically linked with fallacy as its opposite, and faith is linked with disbelief. Therefore, faith, being identified by religious people with truth, cannot include even an assumption of fallacy in faith, for such an assumption is a form of disbelief. In such a context, no theology opposes faith to knowledge. However, in this case, cognition is compared with the assimilation of the texts of the holy books and only from these books the truth about the world and the humans can be revealed to anyone realizing the dogmas of faith as true knowledge.

However, in case we proceed from the fact of clarified understanding of knowledge and its characteristics as a true and reasonable epistemological image, then incorporating the concept of fallacy into the notion of knowledge should be recognized as inappropriate, especially since the withdrawal of fallacy from the sphere of the "competence" of knowledge and its correlation with ignorance, does not imply its exclusion from cognitive processes.

Given the above, such terms as "false knowledge" and "untrue knowledge", which are similar to "round square", are of empty volume, i.e., they have no substantive meaning. On the other hand, all the results of cognitive processes and all mental forms of reflection (including those being at the pre-social level) must be recognized as fallacies if we traditionally consider inadequacy to be the main and the only characteristic of fallacy. Providing such a broad understanding of this phenomenon contradicts the dialectical method, according to which the term "fallacy" is the category fixing the moment of the cognition, which, in essence, is rational and social. Such a circumstance implies the incorrectness of applying this term to psychic images, especially to animal psychic images. Inaccuracy, approximation, incomplete correspondence of the image to the object rather characterize sensation, perception, representation and, generally speaking, all psychic forms of understanding the reality. They do not define the features of fallacy, as it is popularly assumed. In this context, we must note that, in contrast to sensuous reflection, all sensuous forms of cognition are linked, on the one hand, with the visible and targeted reflection of the concrete and, on the other hand, with rational forms of cognition. Homo sapiens not only feel something but also compare each sensation with a concept, a judgment or an inference. That is, they understand WHAT they feel. If they interpret their sensations as inadequate to the objects or the moments of the reality they feel, then fallacies occur: "For a blower hat instead he got a skillet on his head". This shows that fallacy and truth belong to judgments as logical forms of 
knowledge. However, evaluating judgments for being true is not a logical procedure as the practice is the truth criterion.

At the same time, it is impossible to reject the obviously manifested connection between incomplete, inaccurate reflection and fallacy completely. This connection manifests itself in the fact that the degree of adequacy is assessed by the knower, as well as in the case of knowledge. For some reasons (as noted previously) this assessment might be inaccurate. In its turn, such inaccuracy results in the occurrence of subjective exaggeration or underestimation of the degree of adequacy. Furthermore, in such a case, this exaggerated or underestimated measure of the compliance of conformity is represented in absolute terms. An inaccurate assessment of the degree of correspondence of images to their object is, so to say, the "embryo" of fallacy.

Verity is a necessary but insufficient property of knowledge, just as inveracity is a similar characteristic of fallacy. Its final formation occurs when inveracity (overestimated or underestimated assessment of the degree of correspondence) is consolidated in the course of insufficiently complete and rigorous substantiation. The absence of the latter results in the same event.

Nevertheless, the understanding of fallacy differentiated from the knowledge that is offered in this article allows us to remove rigid boundaries between them. Since, on the one hand, the criteria of truth and the value of grounding procedures at different historically defined stages of cognitive processes are different, and, on the other hand, the object of cognition in itself changes, this results in the fact that the same statement about something can be considered either as knowledge or fallacy, depending on some or other conditions. It is remarkable that they were not opposed by Aristotle in due time. He wrote:
"...The same is said here can be true and false. For example, the statement "He is sitting" is true when this is so but then when he is standing up, the same statement is false. The same thing is also true with regard to the opinion: if they correctly believe that a person is sitting, it will be wrong to hang on to this opinion about him when he has stood up" (Aristotle, 1978, p. 31).

Hegel, as is well known, shared a similar point of view. The possibility of mutual transitions between fallacy and knowledge (truth) was outlined by F. Engels. He noted: "Truth and error, like all logical categories moving in polar opposites, have absolute meaning only within an extremely limited area...". In case we have to apply this opposite outside the limits of this area as the absolute one, we will fail completely as both poles of this opposite will turn into their own opposites, i.e., the truth will become fallacy and vice versa" (Engels, 1961 a , p. 92).

In a certain sense, this proposed model of fallacy allows us to differentiate it not only from knowledge, but also from errors and illusions which are close to it, although they do not match it by their very nature.

Most often, the common mindset makes no distinction between them completely. Therefore, all the corresponding concepts can be used as interchangeable ones. Attention to their characteristics in relation to each other is drawn in special research papers and books of reference. For example, it is believed that "fallacy" correlates with a general concept, while "error" is more specific to a generic concept.

Although such a differentiation still does not indicate the meaningful difference between these concepts, it should be recognized that it would be feasible to separate their "spheres" following the principle that the problem of the source and nature of fallacy belongs to philoso- 
phy and the problem of errors belongs to logic and psychology. The outline of this differentiation results from the error as the result of an incorrect theoretical or practical action.

Unlike fallacies, errors take place in thinking, where, in fact, they become logical errors in the definition of concepts, in the provided evidence when the formal rules of thinking are violated. These errors are manifested themselves already at the level of sensuous images in sensations and perceptions, which are sometimes presented as illusions and hallucinations.

In some cases, really existing interdependence and the relationship between fallacy and logical error are not only established but also absolutized. For example, one might say they were identified entirely in medieval scholasticism.

The fallacy was later reduced either to logical errors or to psychic images, inadequate in one or another way. Similar tendencies, influenced by one or another thinker's psychological or logical orientation, lasted until the $19^{\text {th }}$ century. John Stuart Mill, in his well-known work "A System of Logic" (1914) clearly identified fallacies with logical errors resulting from the breaches of the rules of formal logic and using incorrect logical constructions (pp. 633-674).

Error is characterized by inadequacy and incorrectness, while fallacy is defined through inverity and falsity.

Fallacy as an epistemological phenomenon also differs from falsehood which is an intentional desire to mislead someone by suggestion or presumed evidence (justification) and deliberate dissemination of untrue ideas or, more precisely, those ideas, which are considered to be untrue by the disseminator himself, addressed to the subject. In view of the foregoing, we have come to a conclusion already mentioned above that fallacy can be interpreted as unconscious and untrue knowledge, in contrast to falsehood.

Many perplexities and fallacies result from the identification of truth with logicality and even verity.

Falsehood is the opposite of verity, and both of these concepts are categories of ethics. Fallacy, as noted above, is a dialectical partner of truth, and, along with the latter, it belongs to epistemological categories. Logic operates with the concepts of logicality (correctness) and illogicality (incorrectness).

This leads to the conclusion that falsehood and even illogicality can be combined with truth, in contrast with fallacy.

In the context of the above, one cannot but object to A. S. Karpenko arguing simply this in the relevant article of "Contemporary Encyclopedia of Philosophy": "Falsehood is something opposite to truth, something untrue. The phenolmenon of falsehood has four main aspects, such as epistemological, logical, moral and political ones" (Karpenko, 2010, p. 447).

The word "falsehood" is not polysemous but homonymous. Nevertheless, the author of the cited article tries to remove the homonymy by identifying epistemological philosophical, logical, ethical and political meanings of this term. Indeed, in logic, the terms "falsehood" and "false" are used in the meanings which are close to the meanings of terms "incorrect", "wrong", and "illogical". These terms are used in relation to the logical operations of defining a concept, making judgments and inferences. At the same time, logical correctness and logicality are neither a guarantor nor a criterion for the truth of a judgment, as indicated above.

A high scientific level is characterized, first of all, by the use of scientific methodology (systemic approach, including both induction and deduction, the objective logic and history of the 
development, dialectical logic and determinism, etc. in the methods of scientific thought). Only individual specialists and scientists can "grow up" to such a level. They unite in scientific communities. Nevertheless, even they cannot represent a unified system of the scientific worldview and scientific ideology. For thousands of years, this situation has been very favourable for all kinds of falsification of facts. Moreover, at the same time, as in jurisprudence, it is necessary to distinguish voluntary fallacy from deliberate falsification of truth aiming at misleading large groups of people and arming them against each other with the help of false ideology. It should be noted that twin concepts such as "scientific level" and "interhuman/ everyday level" by no means coincide with another pair of terms such as "true ideology" and "false ideology" concerning ideology. Truth can be mastered at the everyday level of knowledge and ideology; on the contrary, the scientific level does not guarantee the truth of ideas. The point is that practice is the criterion of truth, and the logicality of constructing a theory is the criterion of scientific achievements. Thus, of course, Ptolemy's geocentric model of the universe and Copernican heliocentrism belong to scientific ideology because both of them are logically constructed models. However, it is the heliocentric model, which is the only true one. This has already been repeatedly confirmed through practice.

Let us consider some syllogisms in terms of the aspect of formal logic to highlight the problem of the relationship between truth and error in order to dot the i's and cross all the t's.

Our first syllogism is:

All the planets revolve around the Earth.

Venus is a planet.

Venus revolves around the Earth.

Without going into the rules of syllogism inferences, let us note that the syllogism is built correctly. That is, there are signs of logicality. However, today it is not only Copernican heliocentrism that hinders us from recognizing the truth of the above conclusion. This can be seen from already significant practice in the exploring of the solar system. Moreover, it is a practice that is the main criterion for the truth of any assertion.

Let us change the minor premise in this syllogism and receive the following conclusion:

All the planets revolve around the Earth.

The Moon is a planet.

The Moon revolves around the Earth.

In this syllogism, the central premise and the minor premise are not pieces of truth. However, the conclusion is not only made correctly and logically, but it is also a true judgement! This is the discrepancy between truth and logicality, which is demonstrated here quite clearly.

As already noted, truth is a dialectical partner and the antipode of fallacy and there is no concern about falsehood in this regard. Falsehood is a moral and ethical category and its dialectical partner, and the antipode is verity but not the truth.

Truth and falsehood are in no way correlated with truth and fallacy. One can speak the truth and nothing but the truth and write the truth and nothing but the truth is under a delusion at the same time. On the contrary, one can brazenly tell or write lies and still proclaim the truth.

Let us consider the example of the first case. The veracity of things and words is determined by the confidence of speakers and doers who are sure that they are supporters of truth. A. Zhelyabov, S. Perovskaya, N. Kibalchich, N. Rysakov and T. Mikhailov belonging to "Narodnaya Volya" ("The People's Will") group were quite sure that the assassination of tzar Alexander II was a good thing, for it would rock the people of 
Russia and would be a "direct action" for revolutionary transformation. Therefore, oral and written calls and appeals of Narodnaya Volya (The People's Will) members proclaiming for terrorist acts were veracious, but not true. The practice has shown that terror from below can only intensify terror from above.

Now let us consider the example of the second case. If a faithful representative of current astrology (there are still some of them around) truly believing in the veracity of the geocentric universe is accidentally included in a group of the astronomical community, he might pretend to agree with the opinions of the heliocentric model of the universe because of fear for his or her astrological beliefs. In this very case, by telling lies, he expresses a true argument. Arguments and "theories" of false ideology act as weapons in information and ideological confrontation. However, a voluntary fallacy is not an exception, which works more properly only because the one who promotes a harmful idea truly believes in this idea as in a true one (Ogorodnikov, 2019).

\section{Conclusion}

We can draw the following conclusions from the information given in this study:

1) Fallacy is a gnostic result opposite of the truth. Its inveracity is not identified, and in some instances, it is determined by not strict and insufficient ground.

2) Being the dialectical opposite of the truth, fallacy does not only fall out of the processes of cognition but often acts as the essential stage in these processes leading to the truth.

3) It is fallacious to equate fallacy with incomplete knowledge since any knowledge about objective and subjective reality will be necessarily incomplete. Cognition is on the way of discovering singular and the particular, which, being subsequently subjected to systemic synthesis, ensure mastery of truth. In cognition, it is only the elevation of singular and particular to the rank of the universal, which results in fallacy.

4) Furthermore, some philosophical and worldview assumptions used by scientists result in fallacies. Thus, fallacies flow out from objective idealism and subjective idealism. They result in metaphysical (antidialectical) absolutization of either the universal (objective idealism) or the singular (subjective idealism). Such an absolutization leads to the development of perverse criteria of truth and fallacy, respectively.

5) Visuality inherent in many phenomena is often a ground for fallacy in scientific knowledge (as well as in everyday knowledge) is. Visuality is a situation in which a phenomenon "points" to the entity different from the one which is behind this phenomenon. Therefore, one cannot trust sensuous cognition, which is not raised to a rational level.

6) Also, the identification of a conceptual scheme describing the type of a segment of objective reality with this very reality acts as the ground for a fallacy.

7) Fallacy, as well as truth, both exist in judgment-based logical forms. Therefore, it is illogical to refer to psychologically-based grounds for fallacy as well as to be engaged in looking for psychological grounds for truth.

8) It is impossible to equate fallacy with falsehood due to the fact that the latter has verity but not the truth as its dialectical opposite, both referring to moral categories.

9) It is also impossible to equate truth with the 
logicality of thought formation and identify fallacies with logical errors. Although logicality is the criterion of correctness, it is essential but not sufficient condition for receiving truth.

Understanding the essence, causes and conditions for the occurrence of fallacies equips a researcher with tools for understanding and overcoming fallacies on the way to the truth in any area of scientific knowledge.

\section{References}

Aristotel (1978). Sochineniya v 4-x tomakh (Collected Works in 4 volumes, in Russian). (Vol. 2). Moscow: Pensée.

Descartes, R. (1989). Rassuzhdenie o metode dlya rukovodstva razuma $i$ otyskaniya istiny $v$ naukakh (Discussion about the Method for the Guidance of the Mind and the Search for Truth in the Sciences, in Russian). Collected Works in 2 volumes. (Vol. 1). Moscow: Pensée.

Engels, F. (1961 ). Anti-Djuring (Anti-During, in Russian). In K. Marks \& F. Engels, Collected Works (Vol. 20). Moscow: State Publishing House of Political Literature.

Engels, F. (1961 ). Dialektika prirody (Dialectics of Nature, in Russian). In K. Marks \& F. Engels, Collected Works (Vol. 20). Moscow: State Publishing House of Political Literature.

Engels, F. (1961'). Lyudvig Fejerbax $i$ konets klassicheskoi nemetskoi filosofii (Ludwig Feuerbach and the End of Classical German Philosophy, in Russian). In K. Marks \& F. Engels, Collected Works (Vol. 21). Moscow: State Publishing House of Political Literature.
Karpenko, A. S (2010). Lozh (Lie, in Russian). In New Philosophical Encyclopedia. (Vol. 2). Moscow: Pensée.

Kasavin, I. T. (2010). Zabluzhdenie (Fallacy, in Russian). In New Philosophical Encyclopedia, Vol. 2. Moscow: Pensée.

Kondakov, N. I (1975). Logicheskii slovar'spravochnik (Logical Dictionary-Reference, in Russian). Moscow: Pensée.

Leibniz, G. V. (1936). Novye opyty o chelovecheskom razume (New Experiences about the Human Mind, in Russian). Moscow - Leningrad: social-economy published.

Mach, E. (1909). Poznanie i zabluzhdenie (Cognition and Confusion, in Russian). Moscow: published Moscow.

Marks, K. (1962). Kapital (Capital, in Russian). In K. Marks \& F. Engels, Collected Works (Vol. 25). Moscow: State Publishing House of Political Literature.

Mill, J. St. (1914). Sistema logiki (Logic System, in Russian). Moscow: izdatel'stvo G. A. Lemana.

Ogorodnikov, V. \& Oganyan, K. (2020). On the Perceptual, the Conceptual, the Objectively Real and the Problem of Truth in Cosmogony and Cosmology. Wisdom, 1(14), 56-68.

Ogorodnikov, V. P. (2019). Informaciya, ideologiya $i$ istina strukture informacionnogo protivoborstva (Information, Ideology and Truth to the Structure of Information Warfare, in Russian). Proceedings of the Military Space Academy named after A. F. Mozhaisky, 669 (pp. 424-429). Saint Petersburg: Military Space Academy A. F. Mozhaisky.

Plato (1970). Sochineniya: v 3 tomakh (Compositions: 3 Tons, in Russian). (Vol. 2). 
Moscow: Pensée.

Spinoza, B. (1957). Osnovy filosofii Dekarta, dokazannye geometricheskim sposobom (The Basics of Descartes Philosophy,
Proven by Geometric Way, in Russian).

In Selected Works in 2 volumes (Vol.

1). Moscow: State Publishing House of Political Literature. 